\title{
Psychopathological symptoms and predictors among inmates
}

\section{Tarekegn Tadesse Gemeda}

Department of Psychology, Dilla University, Dilla, Ethiopia

Email address:

ttgemeda@yahoo.com

\section{To cite this article:}

Tarekegn Tadesse Gemeda. Psychopathological Symptoms and Predictors among Inmates. Psychology and Behavioral Sciences. Vol. 2, No. 5, 2013, pp. 169-180. doi: 10.11648/j.pbs.20130205.11

\begin{abstract}
The study was meant to examine the prevalence of psychopathological symptoms among inmates, which in line, to suggest systems to accentuate psychosocial rehabilitation program in correction centers. The total number of participants was 420 (i.e., 384 males and 36 females). Multi-stage probability sampling (i.e., stratified, systematic and simple random) sampling techniques were employed, and for the data analysis t-test and logistic regression were applied. It was found that $48 \%\left(\mathrm{CI}_{95}=-0.08,0.05\right)$ of inmates have been experiencing psychopathological symptoms, but not significantly different at $\alpha=0.05, \mathrm{p}=0.65$. Furthermor, a set of predictors reliably distinguished between inmates with and without psychopathological symptoms $\left(\chi^{2}=145.913, \mathrm{p}=0.000\right.$ with $\left.\mathrm{df}=5\right)$. Except gender and age, other variables predicted psychopathological symptom. From the educational status, illiterate $\left(\mathrm{OR}=1.849, \mathrm{CI}_{95}=1.266,2.699\right)$, Grade $1-6(\mathrm{OR}=$ 2.044, $\left.\mathrm{CI}_{95}=1.416,2.951\right)$, and Grade 11-12 $\left(\mathrm{OR}=0.442, \mathrm{CI}_{95}=0.297,0.658\right)$. Also, almost all crime types predicted psychopathological symptoms. That means, killing $\left(\mathrm{OR}=0.280, \mathrm{CI}_{95}=0.211,0.371\right)$, theft and robbery $\left(\mathrm{OR}=0.634, \mathrm{CI}_{95}=\right.$ $0.501,0.801)$, physical attack $\left(\mathrm{OR}=0.367, \mathrm{CI}_{95}=0.278,0.484\right)$ and emotional attack $\left(\mathrm{OR}=0.737, \mathrm{CI}_{95}=0.547,0.994\right)$. From term of sentence, being sentenced for more than 10 years predicted highly $\left(\mathrm{OR}=9.261, \mathrm{CI}_{95}=3.031,28,300\right)$. From district, Sidama $\left(\mathrm{OR}=2.416, \mathrm{CI}_{95}=1.177,4.960\right.$, and Segen district $\left(\mathrm{OR}=2.115, \mathrm{CI}_{95}=1.072,4.175\right)$. Thus, the number of inmates who grieves from mental and behavioral aches remains not nominal. Rehabilitation requires availability, accessibility and integration of professionals (i.e., psychologists, social workers and psychiatrists). Besides, prison tradition essentially duty-bound beyond mundane provisions comparable to shelter, food and medical treatment.
\end{abstract}

Keywords: Psychopathology, Symptoms, Inmates

\section{Introduction}

Over the past decade, a variety of significant reports have presented through convincing empirical evidences on the existence of offensive actions, and the growing rate of mental health problems among inmates, but there have been scanty proofs on the level of psychopathological symptoms among them. Diverse sources of diagnostic estimate on persons with mental illness in jails and prisons were indicated. For example, in America 10 to $15 \%$ [71], in Great Britain over 90\% [8]; and in South Africa 70\% have been stated as inmates [57].

Health problems, mental and behavioral disorders, account for a complex network to engage into offensive actions. Be it anxiety, substance abuse, personality disorders (i.e., psychopathic personality), schizophrenia, mood disorders, and/or any one of the above or co-morbidity breed felonies. One of the empirical evidence has shown that persons who indulge into crime more likely reported earlier frequent medical history [58; 47]. Relatively, similar finding has been drawn from the study conducted by other scholars pointing out on the relationship between substance abuse and offensive actions. That is, cocaine or opioids addictions are remarkably allied to criminal involvement [29], and risky and heavy drinking [47], and illegal drug users [76; 103]. Nagalakshmi, Kasarabada, Anglin, Stark and Paredes [63, p., 67] further explained about substance abuse as inherently a deviant behavior and that has usually co-occur with other abnormal behaviors such as psychiatric illness or crime tendencies among families. Silver, Felson and Vaneseltine [87, p., 417] stated that offenders with a history of victimization (e.g., criminals who already were victim of sexual assault) were more likely to commit assaultive violence than offender who never been victimized. Furthermore, Prins [75, p., 338] described that 
persons charged with a serious offence such as homicide are frequently found to be suffering from severe depressive episode at the time of breaching violence. The South African experience vividly verified the fact as over $70 \%$ of all offenders are currently incarcerated because of violent crimes and possibly some of these offenders experience psychosocial problems [57]. In conclusion, the epidemiological evidence drained from various studies showed that prisoners have experienced and continue to experience worse health problems than the general population $[20 ; 23 ; 65 ; 39 ; 48)$. Further to, the point of discussion in the above section prompted to reach at a conclusive argument, that is, crime, incarceration and mental disorders are directly related. To mean, crime fallouts to incarceration, while incarceration effects to behavioral disorders.

In detail, the kind and nature of psychopathological epidemiology in prison has been poised by diverse scholars as well. For instance, neurotic and depression incidences reported widely $[90 ; 18 ; 17 ; 95]$; anxiety, insomnia and substance abuse with physical ailments such as skin, respiratory and circulatory tract infections [22]. Kinyanjui and Atwoli [49, p., 1] outlined about Kenyan experiences in Eldoret correction center and they expressed that substance abuse was predominant and it was representing $66.1 \%$ in general, while that of alcohol $(65.1 \%)$, cigarette $(32.7 \%)$, cannabis $(21 \%)$, amphetamines $(9.4 \%)$, volatile inhalants $(9.1 \%)$, sedatives $(3.8 \%)$, tranquillizers $(2.3 \%)$, cocaine $(2.3 \%)$, and heroine $(1.3 \%)$. In the study conducted by Houser, Belenko and Brennan [34, p., 799] indicated that the risk of misconduct was higher for inmates with mental illness co-morbid with a drug dependence. Moreover, the impact of substance abuse to provide a pathway between psychosocial characteristics and delinquent decision making among adolescents was discussed [92; 70; 53]. Problems such as agitation; isolation from others; difficulties with eating, sleeping, and self-care; hallucinations and delusions; and difficulties in comprehending or following staff directives are frequently observed among inmates with schizophrenia [71].

The study also raises an enquiry whether the rate of psychopathological symptoms likely to differ through gender, age, educational status, term of sentence, and the weight and nature of crime. The huge literature gap with this regard forced to limit to very few studies. One of them a study undertaken by one of the philanthropic organization, John Howard Society of Alberta [43] denoted that inmates who have been sentenced for long term incarceration experience more deprivations of needs like missing someone, missing social life, worrying about how they will cope, feeling that their lives are being wasted and feeling sexually frustrated. Other scholars presented as dependence on institutional structure and contingencies, hyper - vigilance, interpersonal distrust and suspicion, emotional over-control, alienation, and psychological distancing, incorporation of exploitative norms of prison culture, diminished sense of self-worth and personal value, post-traumatic stress reactions to the pains of imprisonment. In other studies focusing on concurrent variables, age and educational level were examined. That is younger and less educated inmates more frequently experience psychopathological symptoms than adults and inmates from better educational status [28; $46 ; 23 ; 87 ; 49 ; 35]$. As to the relationship between crime weight and psychopathological symptoms; for example, few scholars stated that the problem has become mounted among offenders with heavy crimes like killing and waiting for death row $[19 ; 72]$.

The etiologies have been associated to numerous dynamics (i.e., the widespread misconception that all people with mental disorders are a danger to the public; the general intolerance of many societies to difficult or disturbing behavior; the failure to promote treatment, care and rehabilitation, and, above all, the lack of, or poor access to, mental health services in many countries). Many of these disorders may occur even earlier to prison admission, or to be exacerbated by the stressors in the prison setting. To the contrary, the disorders may well develop right after joining prison yard as a consequence of prevailing conditions and the tortures or other human rights violations [102]. Further to, the non-conducive prison environment, poor rules and regimes governing daily life inside the prison, and very deprived health care [8]. According to Immerwahr and Johnson [36] prisoners have tremendous opportunities to acquire and reinforce negative behaviors since the presence of wide availability of drugs even supplied by the guards themselves, and hence prison can be a "school for crime." These scholars further speculated a step ahead, and that prisoners' face daunting obstacles returning to the community and establishing a noncriminal lifestyle [36]. They likely face - no job, minimal education, few marketable skills, no particular place to go, and very little support/ monitoring, very little chance to learn useful skills. Some researchers from early to date concluded that imprisonment by itself had negative psychological and physical effects on its inmates, leading to psychological deterioration which might be emotional withdrawal, depression, suicidal thoughts or actions and increasing levels of hostility [72]. Prisoners "with mental health illnesses continue to be segregated when they display symptoms of their illnesses." Yet, it is clear that, in many cases, segregation itself is harmful to the person suffering with mental health problem. Every support normally available to prisoners through interaction with their peers is removed. Moreover, the isolation and complete dependence on guards that segregation creates often have an extremely negative impact on prisoners' well-being [76].

Like other domains vis-à-vis rehabilitating and transforming inmates mentally and emotionally has got flimsy attention. For example, meager budget allocation to rehabilitate them indicated by diverse scholars $[15 ; 102$; 24; 56; 60; 89]. Moreover, Cohen and Miller [15, p., 92] explained that criminals were expected to denote about $20 \%$ to $25 \%$ of the entire client population of mental health 
care professionals and the actual costs for mental health services to victims of crime were likely to be between $\$ 5.8$ to $\$ 6.8$ billion; however, various crime victims less likely obtain the proper mental health services.

Treating persons with mental and behavioral disorders is not a linear perspective, and quite different from biomedical treatment approach. Rather, it requires a range of professional integration from varied professional background (i.e., psychiatrists, psychologists, social workers, health workers, occupational therapist as well as other concerned individuals). Kakuma, Minas, van Ginneken, Dal Poz, Desiraju, Morris, Saxena and Sche [44] categorized this group of professionals into three: (1) specialist workers (i.e., psychiatrists, neurologists, psychiatric nurses, psychologists, social workers, and occupational therapists) (2) non-specialist health workers (i.e., doctors, nurse, lay health workers, affected individuals, and care givers) (3) other professionals (i.e., teachers, community based social workers and faith workers). However, the scholars also pointed on the constraint as a lot of countries especially from low and middle income face the challenge to owe these health workers.

Prison and inmates have remained comparable as school and students, where both stand to shape and develop desirable behaviors dropping the trash while holding the fruit .In this regard, correction centers presumed to rehabilitate inmates from multi-dimension (i.e., psychologically, socially, physically, vocationally, and other forms of life skills). Giving emphasis to the psychological rehabilitation, Hitchman [33] outlined about the tranquility garden, artwork, and occupational therapy as a major means for psychological lull. Furthermore, a study undertaken in England constructing Arts and establishing Social Network become unique ways to provide social opportunities for people who experience social exclusion because of their diagnostic labels of personality disorder. Besides, it supports people to make new connections with others who face similar challenges [9]. An experimental type of investigation conducted by Clift and Morrison [14] reflected that group singing can have substantial benefits in aiding the recovery with a history of serious and enduring mental health problems. New perspective for the $21 \mathrm{st}$ century coined by Johnson and Haigh [42] read as a 'psychologically informed environment', or PIE involving the identification of the key features in the family, school, and prison setting foster a sense of belonging.

In Ethiopia treatment alternatives for mental and behavioral disorder predominantly characterized by traditional mode. A study conducted by Ataly, Minilik and Mesfin [3] validated that the traditional healing methods have been widely utilized by the remarkable number of people due to the belief, causes as well as treatments, lie in religious track. Also, availability, accessibility, and affordability of treatment options with passionate and strong convictions persists to such help providers. The scholars further elaborated diverse treatment options as well. For example, (1) wearing amulets (i.e., written scripture on goat skin/ a piece of clothes strip, folded into a tiny bundle, sewn and worn by the patient); (2) Holy Water (i.e., bathing, drinking and sprinkling holy water for days on priest's prescription); (3) Herbal prescriptions (i.e., mixtures of various herbs are given to patients either to chew, drink, or to wear around the neck); (4) Performing rituals (e.g., slaying a cock of particular color, rotating the dead cock round oneself, and then throwing it towards prescribed direction); (5) Exorcism by prayer (i.e., widely used among Moslem and Christians to beseech God for His mercy upon the mentally ill); and (6) Exorcism by fumigation (i.e., to release the possession of evil eye or "buda"). Thus, on the basis of the above preposition the study was meant to achieve the following objectives.

1. To examine the prevalence of psychopathological symptoms among inmates, and to accentuate palatable psychosocial rehabilitation program in the correction centers.

2. To find out whether gender, age, district, educational status, term of sentence and crime type predict psychopathological symptoms.

\section{Method}

\subsection{Participants}

There were 420 inmates who involved in the study. Among which 384 were males, while the remaining 36 were females.

\subsection{Sampling}

The study population included prisoners who have been sentenced at least a month period of time to life long and which accounted 727 (i.e., 667 male and 60 females). The total number of sample size had been 422 prisoners. The sample size was comnuted based on the formula proposed by Hollander, Wolfe and Chicken [34] for single population proportion. The value of " $p$ " was taken as $50 \%$ due to the absence of previous study that indicates the prevalence of psychopathological symptoms. The Z-value of 1.96 was used at $95 \%$ Confidence Interval with margin error was $5 \%$ (i.e., $\mathrm{n}=$ sample size, $\mathrm{p}=$ proportion, $\mathrm{d}=$ margin of error). Accordingly, the sample size (n) of the study was calculated as follows,

$$
n=\frac{z^{2} p(1-p)}{d^{2}}=\frac{(1.96)^{2} \times 0.50 \times(0.50)}{(0.05)^{2}}=384
$$

Also, to manage response set $10 \%$ added to the sample size (i.e., 38 inmates); then, the total sample size contained with 422. Multi-stage sampling (i.e., stratified, systematic and simple random sampling techniques) was employed to randomize the sample selection. The proportion of the sample $(\mathrm{p})=$ Also, to manage response set $10 \%$ added to the sample size (i.e., 38 inmates); then, the total sample size 
contained with 422. Multi-stage sampling (i.e., stratified, systematic and simple random sampling techniques) was employed to randomize the sample selection. The proportion of the sample $(\mathrm{p})=\mathrm{n} / \mathrm{N}$ where, $\mathrm{n}=$ sample size and $\mathrm{N}=$ population size, $\mathrm{P}=\mathrm{n} / \mathrm{N} \quad=422 / 727=0.58$. To refer, 0.58 proportions of participants were obtained from each stratum, bearing in mind, term sentence as a criterion to owe strata. Further elaboration outlined in the following figure, and that was, the sample frame denotes the total number of population size and the number of proportion drawn from each stratum.

\subsection{Research Design and Instrumentation}

A cross - sectional survey design was employed through operating questionnaire as data gathering instrument. CORE psychopathological questionnaire was modified and utilized because it is widely used in clinical practice to assess existing psychological problems and outcome of psychotherapy. The total number of the questionnaire consisted of 29 which were modified statements from 34 CORE survey items. These items were describing feelings and behaviors related to mental and behavior distress. The respondents were asked to check how often they feel or behave that way over the previous week on a five-point scale (i.e., $1=$ Never, $2=$ Twice or once in six month, $3=$ Twice or once in a month, $4=$ Twice or once in a week and $5=$ Daily). Sets of items within the questionnaire relate to overall "subjective wellbeing", psychological "problems", daily "functioning" and "risk" to self and others. A high score labeled as the presence of psychopathological symptoms; which means an individual who scores the average or above the average relatively "unwell", while those scoring below the average "well"

\subsection{Method of Data Analysis}

Single sample independent t-test helped to compare two means (i.e., proportions). The first proportion was theoretically set level of psychopathological symptoms, while the other one was the observed proportion. Moreover, logistic Regression Model was tested the dependent variable (i.e., psychopathological symptoms) against five independent categorical variables (i.e., gender, educational level, district, crime type and term of sentence). Moreover, another continuous variable (i.e., age) was involved to set inmates with psychopathological symptoms. This model was preferred since it is inherently appropriate for the reason that the dependent variable has a dichotomy (i.e., two categories) and suited for epidemiological studies. Further assumptions also deliberated; for example, it suits for the non-linear relationship between the dependent and independent variables.

\section{Results}

This section contains two major components of the study. The first segment exposes the major results cross referencing with the research questions. It has headed-up through analyzing and close-fitting the background data. Independent sample t-test underwent to observe the proportion of psychopathological symptoms among inmates. Additionally, logistic regression was applied to represent whether psychopathological symptoms would be predicted from gender, age, educational status, and term of sentence, district and type of offenses. The continuum of the section focuses on rigorous discussions setting the current findings with research questions and previous literatures. Consistencies and/or contradictions among findings as well as research questions were explained and justified.

\subsection{Participants' Background}

Background data has included age, sex, educational level and district (i.e., from where the participants came from). Age has been reflected to validate, if psychopathological symptoms vary across the maturity level of prisoners, while sex was instrumented to cross - check the amount of psychopathological symptoms among male and female prisoners. The other variable, educational level of inmates, similar to the age of the participant, has been painstaking to underpin the level of psychopathological symptoms with changing age variable. Complementing, districts were taken into account because it was supposed that those variables might affect the prisoner's access and availability of information in the prison to fight against psychosocial distresses. Also, it has supported to check whether the level of psychopathological symptoms differ across it.

Table 1: Participants background data

\begin{tabular}{|c|c|c|c|c|c|c|c|c|c|c|c|}
\hline Age & $\mathbf{N}$ & $\%$ & Gender & $\mathbf{N}$ & $\%$ & $\begin{array}{l}\text { Educational } \\
\text { status }\end{array}$ & $\mathbf{N}$ & $\%$ & District & $\mathbf{N}$ & $\%$ \\
\hline $15-20$ & 133 & 31.67 & \multirow{3}{*}{ Male } & \multirow{3}{*}{384} & \multirow{3}{*}{91.43} & Illiterate & 27 & 6.43 & Gedeo & 296 & 70.48 \\
\hline $21-30$ & 187 & 44.52 & & & & Grade 1-6 & 194 & 46.19 & Sidama & 18 & 4.29 \\
\hline $31-40$ & 61 & 14.52 & & & & Grade 7 - 8 & 32 & 7.63 & Segen & 83 & 19.76 \\
\hline $41-59$ & 34 & 8.10 & \multirow{3}{*}{ Female } & \multirow{3}{*}{36} & \multirow{3}{*}{8.57} & Grade $9-10$ & 109 & 25.95 & Oromiya & 14 & 3.33 \\
\hline$>60$ & 5 & 1.19 & & & & Grade $11-12$ & 29 & 6,90 & Wolita & 9 & 2.14 \\
\hline & & & & & & $>$ grade 12 & 29 & 6.90 & & & \\
\hline Total & 420 & 100 & & 420 & 100 & & 420 & 100 & & 420 & 100 \\
\hline
\end{tabular}


As indicated in the above Table, the majority of inmates who were under the age of 21-30 (i.e., 44.52\%) followed by 15-20 (i.e., 31.67). It can be inferred that the majority of offenders have been under the age of adolescent, early adulthood and middle adulthood stage. It has a huge implication for rehabilitation workers, counselors, policy makers and parents to be conscious about persons who are from such developmental stages in the prevention and intervention programs of crime as well as supporting rehabilitation schemes within prison environment. This entails, identifying "'crime age" which becomes wise decision to embed holistic approach to the development of inmates' career life. Like, crime prone age, better to know " $c r i m e$ prone gender" and that obviously the above finding shows that males, 384 (i.e., 91.43\%) more likely indulged into offensive activities and they found themselves in prison. In the prevention program males should be emphasized since they seem to be more vulnerable due to abnormal childhood socialization, and many more engagements that make them sensitive and bold enough to commit reckless actions.

Furthermore, the many of inmates, 194 (i.e., 46.19\%), were from grade 1-6 (i.e., primary school) followed by grade 9 and 10 (i.e., high school). The rest of inmates fairly came from grade 7 and 8, grade 11 and 12, above grade 12 and the non-educated. The implication seems persons with better educational status correlates with least chance to commit offense, and vis-à-vis. Moreover, in the crime prevention programs as well as in the rehabilitation scheme concerned bodies (i.e., FBOs, CBOs, Government organizations, and Non-government organizations) better to consider the educational level of inmates. In terms of prisoners' district, the majority of them were from Gedeo Zone (i.e., Kochre woreda, Yirga Chefe, Bule and so forth) which constituted, 296 (i.e., 70.48\%) followed by Segen Zone (i.e., Amaro, Burji, Konso and Derashe) owing 83 (i.e., 19.76\%). It would be better still to focus on crime prone areas for better crime prevention, community resilience and organization of safe environment.

\subsection{Prevalence of Psychopathological Symptoms}

Data dichotomization helped to ensure separating inmates with psychopathological symptoms from the nonsymptomatic inmates. Coding " 1 " for the presence, while " 0 " for the absence generated the ultimate result, and helped make to comparison with the theoretical value.

Table 2: Level of psychopathological symptoms

\begin{tabular}{|c|c|c|c|c|c|c|c|c|c|}
\hline $\mathbf{N}$ & Mean & SD & SE & Test V: & .50 & & & & \\
\hline \multirow{3}{*}{420} & \multirow{3}{*}{0.48} & \multirow{3}{*}{0.50} & \multirow{3}{*}{0.033} & \multirow{2}{*}{$\mathbf{t}$} & \multirow{2}{*}{ df } & \multirow{2}{*}{ Sig. } & \multirow{2}{*}{ Mean (-) } & \multicolumn{2}{|c|}{$95 \%$ CI } \\
\hline & & & & & & & & Lower & Upper \\
\hline & & & & -0.458 & 419 & 0.65 & -0.015 & -0.08 & 0.05 \\
\hline
\end{tabular}

In the above Table-2, the proportion of the prisoners who experienced psychopathological symptoms, sample mean 0.48 on the $\mathrm{p}$-value for the test 0.65 . The $\mathrm{p}$-value, 0.65 was greater than the significance level, $\alpha=0.05$. Hence, there was no evidence to conclude as statistically significant difference exists between the theoretical point of psychopathological symptoms and the observed value at 5\% significance level; therefore, the null hypothesis was accepted, $\mathrm{p}=0.50$. In plain understanding, there was evidence to conclude as the rate of psychopathological symptoms was $48 \% \mathrm{CI}_{95}(-0.08,0.05)$.

\subsection{Predictors of Psychopathological Symptoms}

Six variables were considered to predict the probable effect on the psychopathological symptoms among the participants. These variables were gender, age, educational status, term of sentence, district and crime type. Logistic regression was applied to scrutinize the effect of these variables on the inmates' psychopathological symptoms. Within this general model, other specific models were conducted among which Omnibus Tests of Model Coefficients, Classification, and Variables in the Equation. Each of the models has been displayed in the following sections.
Table 3: Omnibus Tests of Model Coefficients

\begin{tabular}{lccc}
\hline & \multicolumn{3}{c}{$\begin{array}{c}\text { Predicted } \\
\text { Symptoms }\end{array}$} \\
Symptoms & Absent & Present & Correct \\
& 1218 & 709 & 63.2 \\
Absent & 845 & 961 & 53.2 \\
Present & & & 58.4 \\
Overall & & & \\
\hline
\end{tabular}

Table-2, above showed that the model, chi-square, was statistically significant with $\mathrm{p}<0.001$. This value showed that all the predictor variables (i.e., gender, age, educational status, crime type and term of sentence) have been impacted on the psychopathological symptoms of inmates.

Table 4: Classification Table

\begin{tabular}{lccc}
\hline & \multicolumn{1}{c}{ Chi-square } & df & Sig \\
\hline Step & 145.913 & 5 & .000 \\
Block & 145.913 & 5 & .000 \\
Model & 145.913 & 5 & .000 \\
\hline
\end{tabular}


The above Table -3 , presented that the classification of Table - 3: Classification Table prisoners who experienced psychopathological symptoms and who did not experience psychopathological symptoms. The proportion of prisoners who did not experience psychopathological symptoms accounted for $63.2 \%$, while inmates that experienced psychopathological symptoms constituted for $53.2 \%$ and the overall proportion had been $58.4 \%$.

Table 5: Variables in the Equation

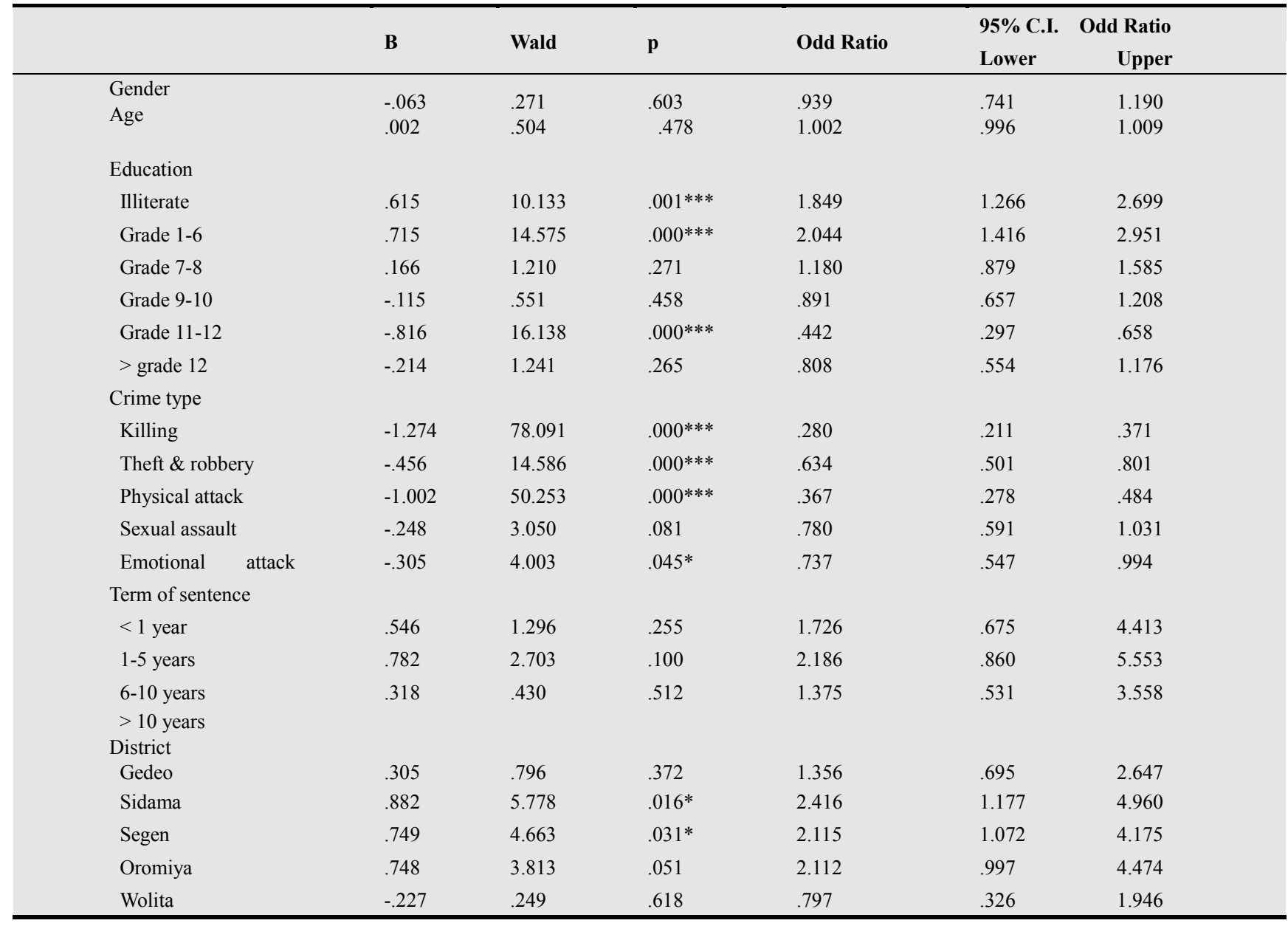

$* \mathrm{p}<0.05, * * \mathrm{p} \leq 0.0001$

Table - 4 describes the amount of each variable contributed to the success of the model (Wald), the significance level and the odd ratio. It was found that all of the variables impacted changes in the psychopathological level of the inmates except gender and age. From the educational status being illiterate with odds (OR $=1.849$, $\left.\mathrm{CI}_{95}=1.266,2.699\right)$, Grade $1-6\left(\mathrm{OR}=2.044, \mathrm{CI}_{95}=1.416\right.$, $2.951)$, and Grade 11-12 ( $\left.\mathrm{OR}=0.442, \mathrm{CI}_{95}=0.297,0.658\right)$. Concerning crime type, almost all kinds of crime brought psychopathological symptoms among inmates. In description, spoiling into killing with odds $\left(\mathrm{OR}=0.280, \mathrm{CI}_{95}\right.$ $=0.211,0.371)$, theft and robbery $\left(\mathrm{OR}=0.634, \mathrm{CI}_{95}=0.501\right.$, $0.801)$, physical attack $\left(\mathrm{OR}=0.367, \mathrm{CI}_{95}=0.278,0.484\right)$ and emotional attack $\left(\mathrm{OR}=0.737, \mathrm{CI}_{95}=0.547,0.994\right)$. Regarding term of sentence, prisoners who have been sentenced for more than 10 years have reported with relatively high psychopathological symptoms with odds $\left(\mathrm{OR}=9.261, \mathrm{CI}_{95}=3.031,28,300\right)$. District as predictor variable, inmates from Sidama area likely experienced psychopathological symptoms $\left(\mathrm{OR}=2.416, \mathrm{CI}_{95}=1.177,4\right.$. $960)$, and from Segen area $\left(\mathrm{OR}=2.115, \mathrm{CI}_{95}=1.072,4\right.$. 175). Further illustration was made through portraying the area covered by each predictor variable on the ROC curve.

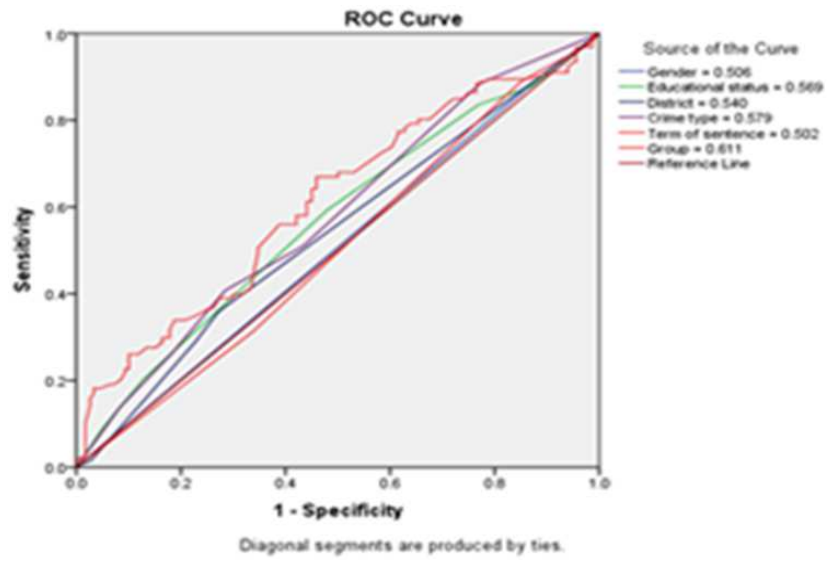

Figure 1: ROC cure for predictors 
The above figure, a measure for goodness - of - fitapplied to evaluate the fit or appropriateness of logistic regression model through simultaneously measuring sensitivity (True positive) and specificity (True negative) for all possible cutoffs and these points plotted on the " $x$ " axis, Specificity, while on the " $y$ " axis, Sensitivity. The area under the curve "ROC curve", Receiver Operating Characteristics, indicated the model fitness. Having this in mind, in the overall area under the ROC curve was 0.611 with $95 \%$ confidence interval $(0.593,0.629)$. Also, the area under the curve was significantly different from 0.5 since $\mathrm{p}<$ 0.001 , that means, the logistic regression classified the group significantly better than the difference occurred due to chance factor. Moreover, the area under the curve for each variable indicated (Gender $=0.506$, Educational status $=$ 0.569 , District $=0.540$, Crime type $=0.579$, and Term of sentence $=0.502$ ).

\section{Discussion}

One of the qualities of scientific research is crafting a holistic meaningful picture connecting and showing the thread off the three pillars of the study, (a) basic research questions, (b) previously conducted related studies and, (c) the current findings. Taking this into account the discussion segment of the study has been chunked into major and sub-topics and which provides clear understanding for scholars who are in the same and/or quite varied disciplines holding diverse purposes.

The prevalence of psychopathological symptoms among inmates was $48 \%, \mathrm{CI}_{95}=-0.08,0.05$ with the $\mathrm{p}$-value for the test 0.65 . The conclusion was the absence of statistically significant differences between the theoretical point of psychopathological symptoms and the observed value. In plain language, it was presumed that the prevalence of psychopathological symptoms was $50 \%$; however, practically was found that $48 \%$ of inmates were experiencing psychopathological symptoms. The nonexistence of statistically significant difference between theoretically estimated values and the observed value proposed firm ground to conclude by means of prisoners' experiences psychopathological symptoms for the duration that they stay at correction center. This might be due to the factors that ingrained into the personality of the prisoners. For example, the social stigma and discrimination that the prisoners obsessed and likely to experience anguish, the guilt feeling for the offensive actions, lack of social support, failing to adapt prison environment (i.e., rules and regulations, the guards' behaviors, the excessive number of crowed in a room) and many more stressors.

The evidence gained from this study, as $48 \%$ of prisoners' experience the symptoms of psychopathology offer inputs to counselors, social workers, health professionals, psychiatrists, and other authorities who are determined to reduce crime through improving the mental and behavioral wellbeing of prisoners. One of the gaps on prisoners' mental and behavioral health services is the presence of scanty studies. Even these flimsy studies do not show the level and kind of psychological disorders especially affecting the psychosocial wellbeing prisoners. The existing inadequate literatures with very few motivated scholars attempting to disclose the presence some psychological disorders such as substance abuse, anxiety, depression, and interpersonal problems $[102 ; 8 ; 72 ; 36 ; 20 ; 23 ; 65 ; 39 ; 48 ; 15 ; 24 ; 56 ; 60$; $89 ; 7 ; 49 ; 92 ; 70 ; 53]$

The impact of the overall predictor variables from the Chi-square model was, $\chi^{2}=145.913, \mathrm{p}=0.000$ with $\mathrm{df}=5$. The overall prediction success was $58.4 \%$ (53.2\% for the presence of psychopathological symptoms and $63.2 \%$ for the absence of psychopathological symptoms). From the Wald criterion analysis, educational status, crime type and district were made significant contributions to prediction ( $p$ $<0.001)$ in all of them.

The relationship between the educational status of prisoners and the level of psychopathological symptoms showed remarkable result. To mean, prisoners who were illiterate, grade 1-6 and grade 11-12 demonstrated more psychopathological symptoms than their counter parts. The idea behind, probably illiterate and prisoners from the lower educational level tended to possess least coping skills, perceiving life as black or white, less interpersonal skills, and self-devaluation while compared to the prisoners who were expected to possess comprehensive cognitive power as life is possible after imprisonment. Moreover, the illiterates and prisoners were who were from low academic background more likely expose themselves to substance abuse and acquire new foreign bad behaviors from the fellow prisoners. This might be due to the difference in the ability to judge desirable behaviors from non-desirable behaviors $[37 ; 46 ; 49 ; 35 ; 87 ; 1)$. This has implication for counselors, psychologists, social workers, health professionals, legal service providers, educators, and further professionals to allow and prioritize inmates from the low educational status. Some other studies generated quite differing findings; for example, [49] claimed psychopathological symptoms more prevalent among educated inmates than the non-educated, which was contrary to the findings of this study.

Crimes such as killing, theft and robbery, physical and emotional attacks predicted the psychopathological symptoms. Although the reason behind criminals who committed such kind of offenses are vulnerable to psychopathological symptoms has become open for further studies, the basic idea lie behind to the trauma load inducing power of the offenses. Crimes such as killing and theft were more probably induce to severe psychological shock than the rest; induce more guilt feeling than the rest and result more social stigma and discrimination than the rest [19). Also, inmates from Sidama and Segen regions reported relatively high level of psychopathological symptoms. This finding shows the status of mental and behavioral disorders even subject to individuals' geographic and social differences. To mean, in some society committing crime, and being jailed for the dues that the person committed of its 
own has been taken as curse and a means of grace from the society. This, in turn, breeds guilt feeling, self-hatred, and stress born physical complaints. Moreover, the social values more likely allow to outcast such persons and the prisoners likely to imagine and foresee the coming post-prison life, with whom and how they can live through overcoming the stigmatic and discriminatory treatments. Term of sentence as predictor variable, inmates who have been sentenced for more than 10 years conveyed significant psychopathological symptoms. This indicates that when prisoners stay in prison more and more the probability of developing mental and behavioral illness is not marginal. This might be due to prisoners more likely feel that they are totally detached from the external social and physical world and observe themselves as born to be imprisoned. The other reason likely to be, as many scholars stated, prison environment across the world has poor quality in terms of crowed and shabby physical setting, ridged and despotic rules and regulations, and the broken and closed interpersonal relationships possibly to escalate the vulnerability to experience psychopathological symptoms.

Thus, psychopathological symptoms of inmates likely to be impacted by gender, term of sentences, age, crime type, district, and educational status, which in turn, establish platform for the development of anguished feelings, destructive thoughts, interpersonal relationship problems, substance abuse and many more non-identified mental and behavioral disorders.

\section{Conclusion}

The output from logistic regression helped to predict psychopathological symptoms for 420 prisoners using gender, age, educational status, crime type, term of imprisonment as predictors. A test of the full model against a constant, three models were statistically significant, representing that the predictors as a set, reliably distinguished between prisoners who experienced psychopathological symptoms and who did not experience psychopathological symptoms $\left(\chi^{2}=145.913, \mathrm{p}=0.000\right.$ with $\mathrm{df}=5$ ).

Over all prediction success was 58.4\% (53.2\% for the presence of psychopathological symptoms and $63.2 \%$ for the absence of psychopathological symptoms). The Wald criterion demonstrated that educational status, crime type and district made significant contributions to prediction success, $p=0.000$. Gender and term of sentence were not significant predictors. Odd Ratio; for example, indicated the growing rate of psychopathological symptoms among illiterate $=1.849$, Grade 1-6 $=2.044$, Grade 11-12 $=0.442$. In similar understanding, the Odd Ration for types of crime showed the increasing level of psychopathological symptoms among inmates who committed killing offense $=$ 0.280 , theft and robbery $=0.634$, physical attack $=0.362$, and emotional attack $=0.737$. Relatively highest growing rate of psychopathological symptoms reported among inmates who have been sentenced for more than ten years $=$
9.261. Furthermore, the rate psychopathological symptoms among inmates who came from Sidamo district were 2.416 and from Segen district were 2.115.

\section{Recommendations}

On the basis of the major findings the following recommendations forwarded:

(1) As the inmates experience psychopathological symptoms, prison centers required to have well organized holistic psychosocial service programs which likely lies into (a) since the number of prisoners increasing, more than one professionally trained counselors were required to be there (b) materially, financially as well as professionally well-organized counseling rooms should be established (c) open, private, and a counseling room that ensures confidentiality required to be organized (d) workers who are working in the correction center need to have positive attitude towards prisoners and requires the skills to support prisoners at their disposal and that they require training and mentoring skills.

(2) The psychosocial rehabilitation program in prison; for example, concerning with availability, accessibility and affordability of programs, plans, and implementations required to base on prisoners' characteristics, nature of crime, nature and term of sentence and the social and physical environment of the prisoners and that refer to:

(a) The nature and type of crime: Inmates who committed serious crimes required immediate follow up, guidance, and social support.

(b) Length of crime sentence: Prisoners who have been sentenced for a range of time suffer more with psychosocial problems and hence need to be given serious attention including vocational training and implementing other forms of rehabilitation schemes.

(c) Educational status of the inmates: Focus on illiterates and inmates with low educational background required to be stressed while conducting intervention activities in the prison centers.

(d) Context based approach: Concerned bodies who are working in prison deemed to rehabilitate inmates psychologically and socially required to consider the geographic and social background of the prisoners. To state, some prisoners likely become sensitive psychologically from certain social and geographic background.

(e) Community sensitization (i.e., involving parents, peer groups, Faith Based Organizations, and others) to have look at in shaping inmates wrong doing through weekly visiting and delivering appropriates social support.

(f) These findings have implication for social workers, counselors, and other professionals who work on the 
mental wellbeing of prisoners required to consider the length of prisoners to stay in the prison. That mean, they need to put in much time, energy, and resources in helping prisoners' sentenced long time since this group of prisoners were more likely exhibit more psychopathological problems than the prisoners who stay short time in the prion.

\section{Acknowledgements}

Inmates in Dilla correction center gain the deepest gratitude for the consent and dedication made through spending their valuable time and energy to offer genuine response for the questionnaires designed to assess the psychopathological symptoms.

The heartfelt recognition further goes to management bodies for allowing and convincing inmates to involve into the study scheme. Furthermore, the attempts that were made to organize the physical and social environment fit to conduct the data collection cherish them valued privilege.

I am also indebted to extend honored respect to Ato Berihun Akeza, who was a psychologist working at the center, for guiding and orienting the inmates to reflect on the questionnaire properly and timely.

\section{References}

[1] Aaltonen, M., Kivivuori, J., and Martikainen, P. (2011). Social determinants of crime in a welfare state: Do they still matter? Acta Sociologica, 54, 161.

[2] Amare D., and Yonas, S. (2005). Awareness and attitude towards common mental health problems, Agaro town, South Western Ethiopia. Ethiopian Journal of Health Sciences. 15(1).

[3] Atalay, A., Menilik,D., and Mesfin, A.(1995). Mental health in Ethiopia. Review Article. Ethiopian Journal of Health Development.

[4] Bandura, A. (1998). Health Promotion from the perspective of social cognitive theory. Psychology und Health, 13, 625-649.

[5] Baker-Ericze, M.J., Jenkins,M.M., and Brookman-Frazee,L .(2010). Clinician and Parent Perspectives on Parent and Family Contextual Factors that Impact Community Mental Health Services for Children with Behavior Problems. Child, Youth Care Forum. 39:397-419

[6] Berry, H. L., Hogan, A., Owen, J., Rickwood, D., and Fragarm, L. (2011). Climate Change and Farmers' Mental Health: Risks and Responses. Asia-Pacific Journal of Public Health, 23(2), 119S-132S.

[7] Bhavsar, V., and Bhugra, D. (2008). Globalization: Mental Health and Social Economic Factors. Global Social Policy, 8(3), 378-396.

[8] Birmingham, L. (2003). The mental health of prisoners. Advances in Psychiatric Treatment. Vol.9: 191-201

[9] Brooker, A. (2011).The Arts and Social Network attachment through art. Mental health and social inclusion.
Pier Professional Ltd. Vol.15 (1)

[10] Budima, G. (2006). Can corruption and economic crime be controlled in developing economies, and if so, is the cost worth it? Journal of Financial Crime, 13(4), 408-419.

[11] Bybee, A. N. (2012). The twenty first century expansion of the transitional drug trade in Africa. Journal of International Affairs, 66(1).

[12] Carter, D. L. (1994). International organized crime: Emerging trends in entrepreneurial crime. Journal of contemporary criminal justice, 10(4), 241-266.

[13] Chi - Hsieh,C., and Pugh, M.D. (1993). Poverty, income inequality, and violent crimes: A Meta-analysis of recent aggregate data analysis. Criminal Justice Review, 18,182.

[14] Clift, S. and Morrison, I. (2011).Group singing fosters mental health and well-being: findings from the east Kent 'singing for health" network project. Mental health and social inclusion. Vol. 15 (2).

[15] Cohen, M.A., and Miller, T.R. (1998). The cost of mental health care for victims of crime. Journal of Interpersonal Violence, 13(1), 93-110.

[16] Colvin, M., Hanley, D., and Flannery, D. (2010). Victimization, Social Support, and Psychological Well-Being. A Study of Recently Released Prisoners. Criminal Justice and Behavior. 37(10):1140-1159.

[17] Cooper, C., and Berwick, S. (2001). Factors affecting psychological well-being of three groups of suicide-prone prisoners. Current Psychology. 20(2):169

[18] Cooper, C., and Livingston, M. (1999). Depression and Coping Mechanisms in Prisoners. Work and Stress. 5:149-154.

[19] Cunningham, M.D., and Vigen, M.P. (2002). Death Row Inmate Characteristics, Adjustment, and Confinment: A Critical Review of the Literature. Behavioral Sciences and the Law.20:191-210.

[20] De Viggiani, N. (2006). A new approach to prison public health? Challenging and advancing the agenda for prison health. Critical Public Health, 16:4, 307-316

[21] DSM-IV (1994). American Psychiatric Association. $4^{\text {th }}$ Edition.

[22] Eytan,A., Haller, D.M., Wolff ,H., Cerutti ,B., Sebo ,P Bertrand D, \& Niveau, G. (2010). Psychiatric symptoms, psychological distress and somatic co morbidity among remand prisoners in Switzerland. International Journal of Law and Psychiatry.

[23] Fazel, S., and Baillargeon, J. (2010). The health of prisoners. Lancet, 377, 956-965

[24] Fitzgerald, C.S. (2011). Theories of crime and delinquency: Findings from an Analysis of Text books on Human Behavior and the Social Environment. Journal of Human Behavior in the Social Environment, 21 212-225.

[25] Gelles, R. J., \& Levine, A. (1999). Sociology: An Introduction. 6th edition, USA: McGraw-Hill College

[26] Ghani, N. A., Mahmud, C. N. (2012). Social Support and Well-being of the Children of Prisoners. Advances in Natural and Applied Sciences, 6(3): 357-364. 
[27] González-Prendes, A. A., and Resko, S.M. (2012) Cognitive- Behavioral Theory. In S. Ringel and J. Brandell (Eds.), Trauma: Contemporary directions in theory, practice, and research (pp., 14-40). Sage Publication, Inc.,

[28] Haney, C. (2002). The Psychological impact of incarceration: Implications for post-prison adjustment. In J. Travis and M. Waul (Eds.), Prisoners Once Removed: The impact of incarceration and reentry on children, families, and communities (pp., 33-65). Washington, D.C., Urban Institute Press

[29] Hammersley, R., Forsyth, A., Morrison, V., and Davis, J.B. (1989). The relationship between crime and opioids use. British Journal of Addiction, 84(9), 1029-1043.

[30] Hartinger-Saunders, R. M., and Rine, C.M. (2011). The Intersection of social process and social structure theories to address juvenile crime: Toward a collaborative intervention model. Journal of Human Behavior in the Social Environment, 21, 909-9925.

[31] Havenaar, J.M., Geerlings, M.I., Vivian, L.A., Collinson, M.A., \& Robertson, B.A (2008). Common mental health problems in historically disadvantaged urban and rural communities in South Africa: prevalence and risk factors. Soc Psychiatry Epidemiology (2008) 43:209-215

[32] Heylighen, F. (1992). A Cognitive - systemic reconstruction of Maslow's theory of self-actualization. Behavioral Science, 37.

[33] Hitchman, M. (2010). Volunteering within acute care seting-its role in promoting hope, recovery and social inclusion. Mental health and social inclusion. Pier Professional Ltd. Vol. 14(2)

[34] Hollander,M., Wolfe, D.A., and Chicken, E.(1999).Nonparametric statistical methods. $2^{\text {nd }}$ Edition. Wiley, Johansson, Incorporated.

[35] Houser, K. A., Belenko, S., and Brennan P. K. (2012). The Effects of mental health and substance abuse disorders on institutional misconduct among female inmates. Justice Quarterly, 29(6).

[36] Imai, S., and Krishna, K. (2004): 'Employment Deterrence and Crime in a Dynamic Model," International Economic Review, 45(3), 845-872.

[37] Immerwahr, J., and Johnson, J. (2002). The revolving door: exploring public attitudes toward prisoner reentry. Prisoner Reentry and the Institutions of Civil Society: Bridges and Barriers to Successful Reintegration. Washington D.C

[38] Ireland, J. L. (2000). A descriptive analysis of self-harm reports among sample of incarcerated adolescent males. Journal of Adolescence. 23,605-613.

[39] Jacob,A. (2011). Economic theories of crime and delinquency. Journal of Human Behavior in the Social Environment, 21,270-283.

[40] James, D. J. and Glaze, L. E. (2006). Mental health problems of prison and jail inmates. U.S. Department of Justice Office of Justice Programs

[41] Jenner, M. S. (2011). International Drug Trafficking: A Global Problem with a Domestic Solution. Indiana Journal of Global Legal Studies, 18, 2.
[42] Johanson, R., and Debrzanska, A. (2005). Mature Copying among Life Sentenced Inmates: An Exploratory Study of Adjustment Dynamics. Corrections Compendium.

[43] Johnson, R. and Haigh, R. (2011). Social psychiatry and social policy for the 21 st century: new concepts for new needs - the 'Enabling Environments' initiative. Mental health and social inclusion. Vol. 15 (1). Pier Professional Ltd. Vol.15 (1)

[44] John Howard Society of Alberta (1999). Effects of long term incarceration.

[45] Kakuma, R., Minas,H., van Ginneken, N.V., R Dal Poz,M., Desiraju, K., E Morris,J., Saxena, S., \& Sche, R (2011). Human resources for mental health care: current situation and strategies for action. Vol. 378 (5)

[46] Kedir, A., and Admasachew, L. (2013). Gender, Place \& Culture: Violence against women in Ethiopia. A Journal of Feminist Geography, 17(4), 437-452.

[47] Kimonis, E. R., Tatar, J. R., and Cauffman, E. (2012). Substance Related Disorders among Juvenile Offenders: What Role Do Psychopathic Traits Play? Psychology of Addictive Behavior, 26(2):212-225.

[48] Kinner, S. A., Dietze, P. M., Gouillou, M., and Alati, R.(2012). Prevalence and correlates of alcohol dependence in adult prisoners vary according to Indigenous status. Australian and New Zealand Journal of Public Health, 36 (4).

[49] Kinsler, P. J. and Saxman, A. (2007). Traumatized offenders Don't look now, But your jail's also your mental health center. Journal of Trauma \& Dissociation, 8:2, $81-95$.

[50] Kinyanjui, D.W.C., and Atwoli, L. (2013). Substance use among inmates at the Eldoret prison in Western Kenya. BioMed Central Psychiatry 13 (53).

[51] Kirchner, T., Forns, M., and Mohino, S. (2008). Identifying the Risk of Deliberate Self-Harm among Young Prisoners by Means of Coping Typology. Suicide and Life-threatening Behavior, 38(4)

[52] Kohfeld, C.W., and Spraguue,J. ( 1988). Urban unemployment drives urban crimes. Urban Affair Quarterly, 24(2), 215-241

[53] Ksenia, G. (2008). Can corruption and economic crime be controlled in developing countries and if so, is it cost-effective? Journal of Financial Crime, 15(2), 223-233.

[54] Kubiak, S.P., Boyd, C.J., Janie Slayden, J., \& Young, A. (2005). The Substance abuse treatment needs of prisoners. Journal of Offender Rehabilitation, 41:2, 1-19.

[55] Lake, J. (2007). Integrative Mental Health Care: From theory to practice, Part 1. Alternative Therapies in Health and Medicine. 13(6):50.

[56] Laub, J.H., and Sampson, R.J. (2003). Shared beginning, Divergent lives: Delinquent boys to age 70. Cambridge: Harvard University Press. Chapter 6-10.

[57] Lennox, C., , Senior , J., King , C., Hassan , L., Claytona,R.,Thornicroft,G., and Shawa,J. (2012). The management of released prisoners with severe and enduring mental illness. The Journal of Forensic Psychiatry \& 
Psychology, 23(1), 67-75.

[58] Loots, S., and Louw, D. (2011). Antisocial personalities: Measuring prevalence among offenders in South Africa. South African Crime Quarterly, 36.

[59] Mateyoke-Scri, A., Webster, J. M., Hiller, M. L., Staton, and M. Eukefeld (2003). Criminal history, physical and mental health, substance abuse, and services use among incarcerated substance abusers. Journal of Contemporary Criminal Justice, 19(1), 82-97.

[60] Mckenzie, K. (2008). Urbanization, social capital and mental health. Global Social Policy, 8(3), 359-377.

[61] Mitchell, J., and Latchford, G. (2010). Prisoner perspectives on mental health problems and help-seeking. The Journal of Forensic Psychiatry \& Psychology, 21(5), 773-788.

[62] Moor, M. and Morris, M.B. (2011). Psychological theories of crime and delinquency. Journal of Human Behavior in the Social Environment, 21,226-239.

[63] Muntaner, C., Eaton, W.W., \& Diala, C.C. (2000). Social inequalities in mental health: a review of concepts and underlying assumptions. Health (London), 4:89.

[64] Nagalakshmi D., Kasarabada, M., Anglin, D., Stark,E., and Paredes, A. (2000). Cocaine, Crime, Family History of Deviance-Are Psychosocial Correlates Related to These Phenomena in Male Cocaine Abusers? Substance Abuse, $21: 2,67-78$

[65] Nystuen, P Hagen, K. B. and Herrin, J. (2001). Mental health problems as a cause of long-term sick leave in the Norwegian workforce. Scandinavian Journal of Public Health, 29, 175-182.

[66] Ogloff, J., Warren,L., Tye ,C., Blaher, F ., and Thomas, S. (2011) .Psychiatric symptoms and histories among people detained in police cells. Social Psychiatry Psychiatric Epidemiology, 46,871-880.

[67] Olin , S.S., Hoagwood , K.E., Rodriguez, J., Ramos , B., Burton ,J., Penn, M., Crowe , M., Radigan, M., and Jensen, P.S. (2010). The Application of Behavior Change Theory to Family-Based Services: Improving Parent Empowerment in Children's Mental Health. Journal of Child and Family Studies. 19:462-470.

[68] Olatunbosun, A., and Oluduro, O. (2012). Crime Forecasting and Planning in Developing Countries: Emerging Issues. Canadian Social Science, 8(1), 36-43.

[69] Orsagh, T. and Chen, J.R. (1988). The effect of time served on recidivism: An interdisciplinary theory. Journal of Quantitative Criminology, 4(2), 155-171.

[70] Otusanya, O. J. (2011). Corruption as an obstacle to development in developing countries: A review of literature. Journal of Money Laundering Control, 14(4), 387-422.

[71] Oxelson, E. (2009). Mental health treatment in a state prison: Managing challenges. Journal of Groups in Addiction \& Recovery, 4:4, 288-305

[72] Peters, R.H., Sherman, P.B., \& Osher, F.C. (2008). Treatments in jail and prison

[73] Picken, J. (2012). The coping strategies, adjustment and wellbeing of male inmates in the prison environment. Internet Journal of Criminology
[74] Piquero, N.L., and Benson, M.L. (2004). White-Collar Crime and Criminal Careers: Specifying a Trajectory of Punctuated Situational Offending. Journal of Contemporary Criminal Justice, 20,148.

[75] Polk, K., and White, R. (1999). Economic adversity and criminal behavior: Rethinking youth unemployment and crime. Australian \& New Zealand Journal of Criminology, 32,248 .

[76] Prins, H. (2005). Mental disorder and violent crime: A problematic relationship. The Journal of Community and Criminal Justice, 52(4), 333-357.

[77] Prison Justice Day Committee (2006). Abolish prisons. E. Broadway Vancouver, B. C. V5N $5 \mathrm{~W} 1$. www.prisonjustice.ca

[78] Quinn, J. F., and Sneed, Z. (2008). Drugs and crime: An empirically based, interdisciplinary model. Journal of Teaching in the Addictions, 7:1, 16-30.

[79] Reamer, F. G. (2007). Responding to heinous crime: Best practices and the current state of the art, victims and offenders. An International Journal of Evidence-based Research, Policy, and Practice, 2:4, 307-326

[80] Robert, C. R., Vallerand, J., and Provencher, P. (2004). Cognitive adaptation and mental health: A motivational analysis. European Journal of Social Psychology, $34,459-476$

[81] Robbins, M. (1992). Psychoanalytic and Biological Approaches to Mental Illness: Schizophrenia. Journal of the American Psychoanalytic Association, 40,425.

[82] Rosenstock, I. M., Strecher,I.J., and Becker, R.H. (1988). Social Learning Theory and the Health Belief Model. Health Education Quarterly, 15(2), 175-183.

[83] Sauter, F.M, Heyne, D, Westenberg, P.M. (2009). Cognitive Behavior Therapy for Anxious Adolescents: Developmental Influence on Treatment Design and Delivery. Clinical, Child and Family Psychology Review. 12:310-335.

[84] Seipel ,M. M.O. (1999). World mental health Problems and perspective. International Social Work, 42(4), 407-418.

[85] Sharp, S. F. Marcus-Mendoza, S. T., Bentley, R. G., Simpson, D. B., and Love, S. R. (1995). Gender Differences in the Impact of Incarceration on the Children and Families of Drug Offenders. Journal of the Oklahoma Criminal Justice Research Consortium. Vol. 4

[86] Shawe-Taylor, M (2010). Towards the Development of an Integrated CBT Provision within a Large Organization Offering Services to People with Mental Health Problems and/or Learning Disabilities. Psychological Topics. 19(2):387-399

[87] Shoemaker. D. J. (2005). Theories of delinquency: An examination of explanations of delinquent behavior. New York: Oxford University Press.

[88] Siegel, J. M., Golding, J. M., Stein, J. A., Burnam, M. A., \& Sorenson, S. B. (1990). Reactions to sexual assault: A community study. Journal of Interpersonal Violence, 5, $229-246$

[89] Silver, E., Felson, R. B., and Vaneseltine , M. (2008). The relationship between mental Health problems and violence 
among criminal offenders. Criminal Justice and Behavior, 35(4), $405-426$

[90] Singleton, N., Meltzer, H., Gatward, R., Coid, J. \& Deasy, D (1998). Psychiatric morbidity among prisoners in England and Wales: the report of a survey carried out in 1997 by Social Survey Division of the Office of National Statistics on behalf of the Department of Health. London: The Stationery Office, 1998.

[91] Shinkfield, A., Graffam, A., and Meneilly, S. (2009). Co-Morbidity of conditions among Prisoners. Journal of Offender Rehabilitation, 48:4, 350-365.

[92] Singleton N, Meltzer H, Gatward R, Coid J, Deasy (1998). Psychiatric morbidity among prisoners in England and Wales TSO: London

[93] Smith, P. S. (2008). "DEGENERATE CRIMINALS": Mental Health and Psychiatric Studies of Danish Prisoners in Solitary Confinement, 1870-1920. Criminal Justice and Behavior, 35 (8), 1048-1064.

[94] Solomon, H., Fasil, T., Mekonen, A., Henok, T. and Girma, T. (2012). The prevalence of depression and associated factors in Ethiopia: Findings from the National Health Survey. International Journal of Mental Health System, 6, 23.

[95] Solomon, B. J., Campero, J., Llamas, J., and Sweetser, C. B. (2012). Psychosocial Contributors to Delinquent Decision Making: Toward a Conceptual Framework for Adolescent Female Offending. Women \& Criminal Justice, 22,265-288.

[96] Song, L., and Lieb, R. (1993). Recidivism: The Effect of Incarceration and Length of Time Served. Washington State Institute for Public Policy

[97] Swartz, J. A. (20011). Chronic Medical Conditions among Jail Detainees in Residential Psychiatric Treatment: A Latent Class Analysis. Journal of Urban Health: Bulletin of the New York Academy of Medicine. 88(4)
[98] Sudbery, J., and Blenkinship, A. (2005): 'Acting as a good parent would'? Journal of Social Work Practice: Psychotherapeutic Approaches in Health, Welfare and the Community, 19:1, 43-57

[99] Taylor, S.E. (1983).Adjustment to threatening events: A theory of cognitive adaptation. American Psychologists, $38(11)$.

[100] Walsh, R.N., and Vaughan, F. (1980). Beyond the Ego: Toward transpersonal models of the person and psychotherapy. Journal of Humanistic Psychology, 20, 5.

[101] Wasserman, E. A., and Miller, R. R. (1997). What's elementary about associative learning? Annual Review of Psychology, 48,573-607.

[102] Weisburd,D., Chayet, E.F., Waring, E.J. (1990). White collar crime and criminal careers: Some preliminary findings. Crime and Delinquency, 36, 342.

[103] Weiss, S. J., Haber, J., Horowitz, J. A., Stuart, G. W., and Wolfe, B. (2009). The Inextricable Nature of Mental and Physical Health: Implications for Integrative Care. Journal of the American Psychiatric Nurses Association, 15, 371.

[104]WHO and ICRC (2005). Mental health and prison. Information sheet

[105] Wunsch M.J., Nakamoto K., Goswami , A., \& Schnoll, S.H. (2007). Prescription drug abuse among prisoners in rural southwestern Virginia. Journal of Addictive Diseases, 26:4 $15-22$.

[106] Yoseph, E., Mebratu, G., and Belete, R. (2006). Assessment of trafficking in women and children in and from Ethiopia. IOM (International Organization for Migration)

[107]Zembroski, D. (2011). Sociological theories of crime and delinquency. Journal of Human Behavior in the Social Environment, 21,240-254. 